\title{
Left superior vena cava draining to left atrium with partially anomalous pulmonary venous connection and left-to-right shunt - multimodality imaging and percutaneous treatment
}

\author{
Kaisa Ylänen ${ }^{1}$, Linda Litwinn ${ }^{1,2}$, Tiina Ojala ${ }^{1}$, Juha Puntila³ ${ }^{3}$ Teija Kalajoki-Helmiö ${ }^{4}$, Jaana Pihkala ${ }^{1}$ \\ ${ }^{1}$ Department of Pediatric Cardiology, Children's Hospital, University of Helsinki and Helsinki University Hospital, Helsinki, Finland \\ 2Department of Congenital Heart Defects and Pediatric Cardiology, SMDZ in Zabrze, Silesian University Medical in Katowice, Poland \\ ${ }^{3}$ Department of Pediatric and Transplantation Surgery, Children's Hospital, University of Helsinki and Helsinki University Hospital, Helsinki, \\ Finland \\ ${ }^{4}$ Department of Radiology, Helsinki Medical Imaging Center, Children's Hospital, Helsinki, Finland
}

Adv Interv Cardiol 2018; 14, 3 (53): 312-313

DOI: https://doi.org/10.5114/aic.2018.78338

A 4-year-old asymptomatic girl with systolic murmur was referred to a pediatric cardiologist. Transthoracic echocardiography revealed persistent left superior vena cava (LSVC) with a communication to the left atrium (LA) and flow directed upwards to the bridging vein introducing a left-to-right shunt. There was no interatrial communication. The coronary sinus was normal, and there was a hemiazygos vein draining to the LSVC.

Previously introduced cases with the LSVC draining directly to the LA have demonstrated a right-to-left shunt and a risk of paradoxical thromboembolism [1-4]. The left-to-right shunt detected in our patient was confusing. Therefore, cardiac magnetic resonance imaging (MRI) and computed tomography (CT) were programmed.

Magnetic resonance imaging detected a QP : QS ratio of 1.6 and increased volume of the right ventricle (Z-score +4$)$.

Cardiac CT confirmed the LSVC to LA connection with a suspicion of the left upper pulmonary vein (LUPV) draining to the LSVC. Cardiac catheterization with hemodynamic measurements and LSVC and pulmonary wedge angiograms was performed. Angiograms confirmed an unobstructed connection of the LSVC to the LA. The LUPV drained to the LSVC with the flow towards both the bridging vein and the LA (Figure 1). Pressure measurements were normal: right atrium $7 / 5 / 5 \mathrm{~mm} \mathrm{Hg}$, right ventricle $24 / 6 \mathrm{~mm} \mathrm{Hg}$, and left ventricle $88 / 8 \mathrm{~mm} \mathrm{Hg}$. The oxygen saturation measured $99 \%$ in the LSVC, $79 \%$ in the right superior vena cava (RSVC) high above the junction with the bridging vein, $87 \%$ in the pulmonary artery and $99 \%$ in the left ventricle with a QP : QS ratio of 1.67. An Amplatzer Duct Occluder device (12/10 mm) was placed in the LSVC below the hemiazygos vein - just above the orifice of the LUPV - thereby redirecting the LUPV flow to the LA.

Cardiac MRI, CT and transthoracic echocardiography are well established in determining pulmonary and systemic venous drainage. In this case, cardiac catheterization confirmed the connection of the LUPV to the LSVC and explained the left-to-right shunt which then could be closed percutaneously.

\section{Conflict of interest}

The authors declare no conflict of interest.

\section{Corresponding author:}

Linda Litwin, Department of Congenital Heart Defects and Pediatric Cardiology, SMDZ, Silesian University Medical, 9 M. Curie-Sklodowskiej St, 41-800 Zabrze, Poland, phone: +48 784053 435, e-mail: linda.litwin@med.sum.edu.pl

Received: 16.02.2018, accepted: 11.04.2018. 

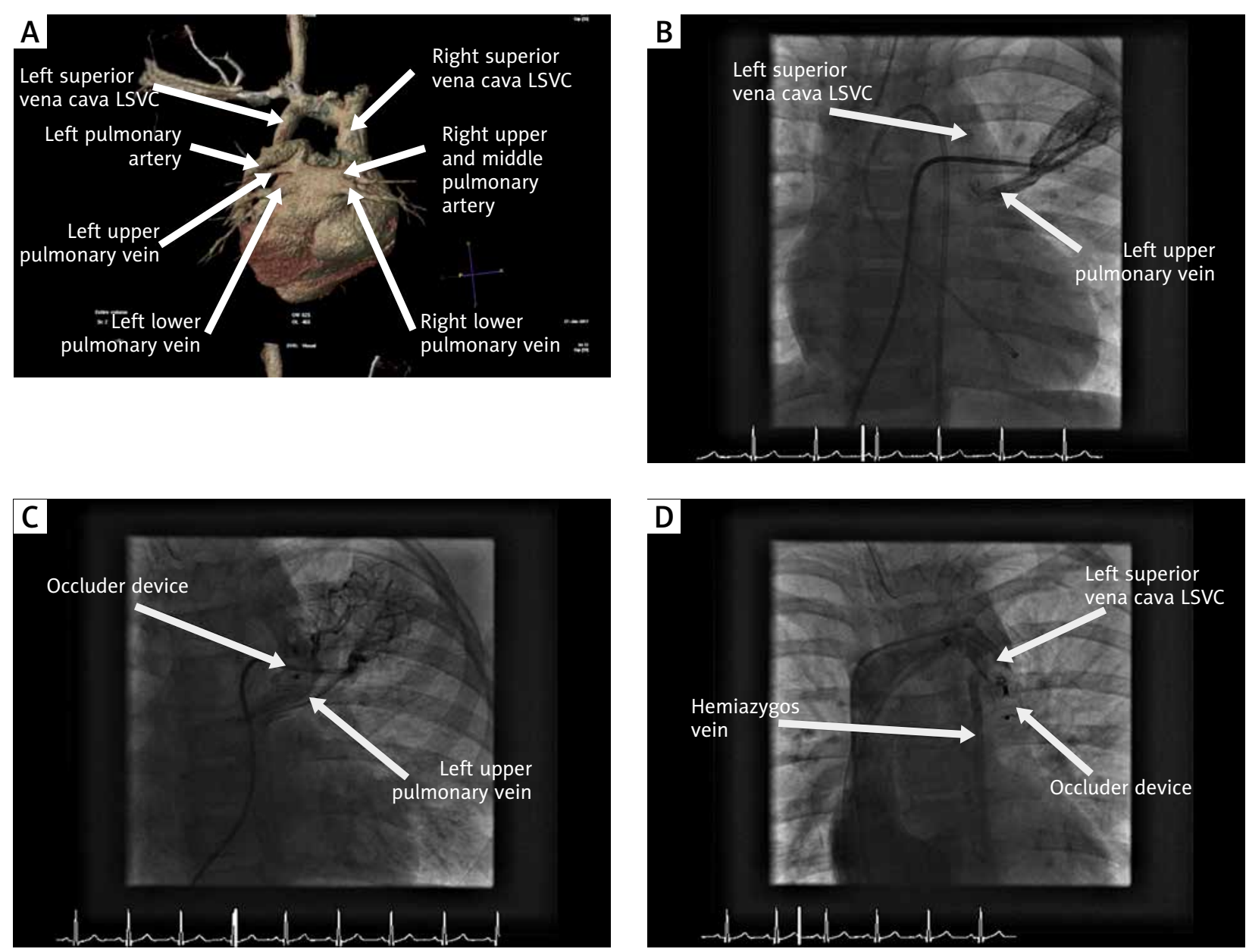

Figure 1. A-Computed tomography reconstruction: the left superior vena cava draining to the left atrium with a suspicion of the left upper pulmonary vein draining to the left superior vena cava, B - angiography: the left upper pulmonary vein draining to the left superior vena cava with the flow towards both the bridging vein and the left atrium, C, D - Angiography after implantation of an Amplatzer Duct Occluder device (12/10 mm) in the left superior vena cava, below the hemiazygos vein and just above the orifice of the left upper pulmonary vein, with the left upper pulmonary vein flow redirected to the left atrium

\section{References}

1. Moustafa S, Patton DJ, Merchant N, et al. Successful catheterbased occlusion of persistent left-sided superior vena cava draining into the left atrium. Eur Heart J Cardiovasc Imaging 2012; 13: 122.

2. Hutyra M, Skala T, Sanak D, et al. Persistent left superior vena cava connected through the left upper pulmonary vein to the left atrium: an unusual pathway for paradoxical embolization and a rare cause of recurrent transient ischaemic attack. Eur J Echocardiogr 2010; 11: E35.

3. Tampere L, Paranon S, Séguéla PE. Percutaneous closure of a left superior vena cava draining directly into the left atrium in a child. Arch Cardiovasc Dis 2012; 105: 53-5.

4. Quarti A, Di Eusanio M, Pierri MD, Di Eusanio G. Left superior vena cava draining into the left atrium, associated with partial anomalous pulmonary venous connection: surgical correction. J Card Surg 2005; 20: 353-5. 